\title{
Real-time and low-cost IoT based farming using raspberry $\mathrm{Pi}$
}

\author{
Wahidur Rahman ${ }^{1}$, Elias Hossain ${ }^{2}$, Rahabul Islam ${ }^{3}$, Harun-Ar-Rashid $^{4}$, Nur-A-Alam ${ }^{5}$, \\ Mahmodul Hasan ${ }^{6}$ \\ 1,3,4,5,6 Department of Computer Science and Engineering, \\ Mawlana Bhashani Science and Technology University, Bangladesh \\ ${ }^{2}$ Department of Software Engineering, Daffodil International University, Bangladesh
}

\begin{tabular}{l} 
Article Info \\
\hline Article history: \\
Received May 20, 2019 \\
Revised Jul 18, 2019 \\
Accepted Aug 3, 2019 \\
\hline Keywords: \\
Dashboard \\
IoT (Internet of things) \\
IP-camera \\
pH \\
Sensor
\end{tabular}

Sensor

\begin{abstract}
This paper reflects on the implementation of IoT enabled Farming, especially for the people needed a smart way of agriculture. This research focuses on real-time observation with efficient use of cheapest security system. The features of this research including i) Sensor data monitoring using soil moisture sensor which is responsible for measuring moisture of the filed, water level sensor which is liable for detecting flooded water, $\mathrm{pH}$ sensor which is accountable for measuring $\mathrm{pH}$ of the soil and Temperature and humidity sensor which is responsible for tracking out the present temperature and humidity in the atmosphere ii) Live monitoring of sensor's values using cloud and a Dashboard iii) Security issues of the farming using Laser shield and IP-Camera through Wi-Fi which is conducted by android application. This paper also assures the analysis of the experimented data based on various sensor's values and gives a momentous way for future applications. Result and discussion aslo ensure the contribution in the field of Internet of things.
\end{abstract}

Copyright $\odot 2020$ Institute of Advanced Engineering and Science. All rights reserved.

\section{Corresponding Author:}

Md. Wahidur Rahman,

Department of Computer Science and Engineering,

Mawlana Bhashani Science and Technology University,

Santosh, Tangail, Dhaka, Bangladesh-1902.

Email: wahidtuhin0@gmail.com

\section{INTRODUCTION}

In accordance with World Bank data in the year 2013, it is calculated that the growth of $1 \%$ of GDP comes from agriculture. Again, according to FAO, $60 \%$ people around the world directly depend on agriculture. At present $11 \%$ or 1.4 billion of world's land is used in crop production. Moreover, recent census on world's population in year 2019 shows that 7.7 billion people live around the world. The growth of population results in reduction of cultivated land.

So, we need to apply the knowledge of technology and recent inventions in the field of agriculture, especially in the farming sectors for better outcomes. On the other hand, the world's market of IoT is presage to be worth $\$ 1.8$ Trillion in the year 2020. IoT can also be applicable in the field of socio-economic sectors. But IoT is barely used in the field of agriculture. In present scenario, farmers are believe in ancient way of production of crops in their fields. IoT can be great solution for both production and security issues. Moreover, in some developing and poor countries around the world are residing under poverty. They have a little knowledge what is going on in the present world, how to apply science and technology in their regular life. On the contrary, IoT technology offers an efficient solution in our regular purposes. If we use IoT in the field of production of harvest as well as several sections in agriculture, the solution would be better, more adjuvant as well as handy.

To work with IoT properly we have to take a simplest and cost effective solution. Raspberry Pi based solution offers easiest way to achieve the blessing of IoT. As pursuant to internet, Raspberry Pi is 
credit-card sized computer with very low cost and greatest features. It has building Wi-Fi which is called the core of IoT. Though it is operated through Python language, Raspberry Pi provides great performance for both IoT and cloud computing. Raspberry pi also secures a way of server based applications. There is a method to work with raspberry pi in the field of agriculture by connecting various sensors whose are required for farming.Further on we can also find an IoT solution as well as live monitoring through dashboard.

\section{REVIEW LITERATURE}

The proposed system [1] developed a fully computerized observation in the space of agriculture that would considerably decrease human efforts and progress the crops quality. This proposed system provides a perfect conservative solution on environment. The sensors data are responsible to make a relationship among water content, temperature, light etc.

The paper [2] developed an algorithm for their system. The main improvement of the proposed system is that it has ability to send data of soil to the corresponding users through IoT technology for irrigation. Soil moisture measuring device processes water gratified of soil and produced result is served to the amplifier which is offering to develop the expansion of values. This value is specified to Arduino Uno as analog input data. LDR and laser produce second analog input data which successively fed to Arduino Uno. These two analog contributions are transformed to numerical output values by Arduino Uno.

The proposed system [3] experimented with sevral types of sensors such as $\mathrm{pH}$, soil moisture, DHT11, PIR and pressure sensors. All are integrated to the involvement of Arduino microcontroller. Detected values of these sensors are shown in LCD screen. If the detected values go elsewhere, the staring values set in the program and corresponding pump will be spontaneously switched ON/OFF by communicating the circuit. The whole configuration is connected to the motorist circuit which leads to adjustment of voltage. The farmer will be informed about what is current situation in the field using GSM as wel as reorganized web pages. Through the proposed system, the agriculturalist can access the details about present situation of the ground whenever at a particular time period.

The paper [4] focused on IOT based Smart Irrigation model for agriculture using Raspberry Pi. This is a smart solution to overcome the employment of rigorous work and also controls water supervision system. The main purpose of this paper is to reduce conservative method and maintain genuine technique of water ingesting which leads to proper irrigation system. Again, this solution will decrease water consumption and avoid ventilation up of tanks, rivers etc. Main scope of this proposed system is to avoid decline of yields which will destroy our agricultural efficiency. The paper also expresses programmed exploitation and provides a way to control amount of water. The proposed system used android application as user interface component, where users are able to deliver the involvement and select seed based on the ground.

The paper [5] designed an Intelligent IoT based model which is effectively called automated irrigation system. The authors used several type of sensors where information are concerning to soil moisture, hotness. Here, KNN (K- Nearest Neighbor) arrangement machine learning algorithm is used to arrange for investigating the sensor data in order to estimate moistening of soil along with water. The proposed system offers a fully computerized architecture where devices are interconnected among themselves and apply required intellect in the field of irrigation.

The aim of the paper [6] is to reduce time and energy and makes regular life easier to the farmers. The proposed system is designed especially for the farmers where farmers are able to understand their field status. This system was developed for optimizing water management and production of agricultural crops. The core part of this model is the involment of Raspberry Pi. The objectives of this paper remained to control the water pump automatically, monitor the herb growing using webcam and can also lookout live streaming of farmhouse on smartphone through Wi-Fi.

The proposed system [7] used several types of sensors such as soil moisture sensor and temperature and humidity sensor and ultrasonic sensor. This proposed system is basically basd on Raspberry pi which leads to an automated system such that if soil moisture or hotness constraints cross a predefined inception level, automated system send the value to Raspberry Pi. Atfer receiving the value, the relays whose are integrated to raspberry pi will try to ON or OFF the motors. This paper developed an effective, honestly cheap and easy automatic irrigation.

The paper [8] developed an IOT based smart irrigation system which was designed for home based organic garden. The purpose of this paper was to develop a water management method for a garden. A methodical irrigation development algorithm is used to establish as per the necessity of the user. This paper also aims at the progress of weather based on irrigation model through an inception.

The authers proposed a system [9] which is a combination of hardware and software mechanisms. The hardware portion contains of embedded system and required software are webpages which is designed 
by PHP. The webpages are hosted on online and contains a databank which is the impressions from sensors are injected through hardware.

The paper [10] proposed a garden Irrigation system using Raspberry Pi. Basically the paper concentrated on greenhouse technology. Currently, many scientists have invented greenhouse technology with home automation system and named it as smart home watering or irrigation system. The goal of this system is to observe and control vegetal growth in home garden area constructed on ecological issues.

\section{WORKING PRINCIPLE}

Basically, our proposed system [11-22] is divided into some inter-connected parts . First of all we have given all our concentration on setting up circuit design. We have connected several types of sensors with raspberry pi using wires in a direction towards schematic diagram. Secondly, sending all the sensors data to the cloud in order to insure live monitoring. Finally, we have ensured the security of the firm using IP-camera and cost effective Laser shield.

\subsection{Connection of Sensors to Raspberry Pi}

Actually, we have used four types of agriculture related sensors such as soil moisture sensor, $\mathrm{pH}$ sensor, water level sensor and Humidity/temperature sensor. We have connected soil moisture sensor as shown in the Figure 1. Analog pin of soil moisture sensor is connected to MCP3008which leads to analog to digital conversion of dada. Then a wire from MCP3008 is contacted to GPIO pin of raspberry pi. In this part we have used 5V dc supply as well as GND pin of Pi.

The working procedure of soil moisture sensor is as same as Figure 2. Here, raspberry pi first check the status of connection. If the connection is available, the system starts reading moisture data of soil. If there is a missing of connection of wires, it send a non-comitial reply to the users.

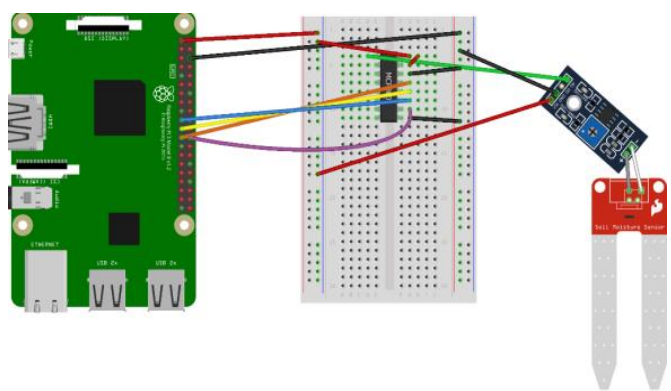

Figure 1. Circuit diagram of soil moisture sensor

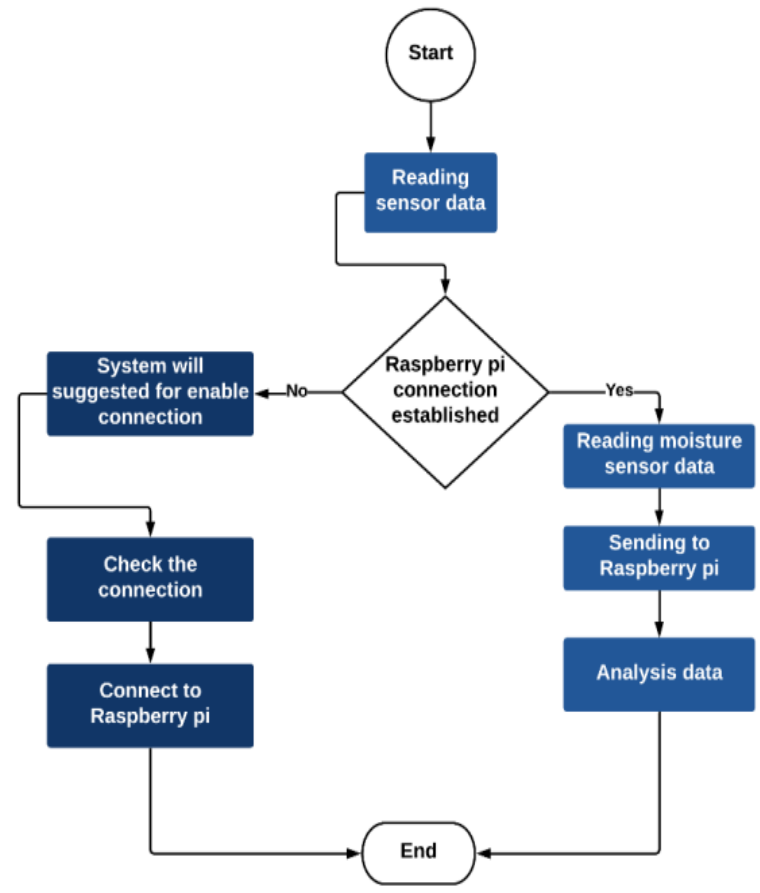

Figure 2. Flow chart for connecting Moisture sensor to Pi

We have assured the connection of $\mathrm{pH}$ sensor for calculating $\mathrm{pH}$ of soil. We do the same procedure as describe in the section of soil moisture sensor. The working procedure of $\mathrm{pH}$ sensor much like as Figure 3 Flow chart. In this section, when raspberry pi finds the connection status available, it starts reading analog value and covert the value using MCP3008. In case of failure of connection it sends predefined message to user end. 
After successfully connecting the $\mathrm{pH}$ sensor to raspberry pi, we have connected water level sensor. Basically, water level sensor use to detect overflow of water in the field. It sends pi only the binary value either " 0 " or " 1 ". Sooth to say, we use this sensor to detect much amount of water crossing the limit. The working criteria is much like as following Figure 4.

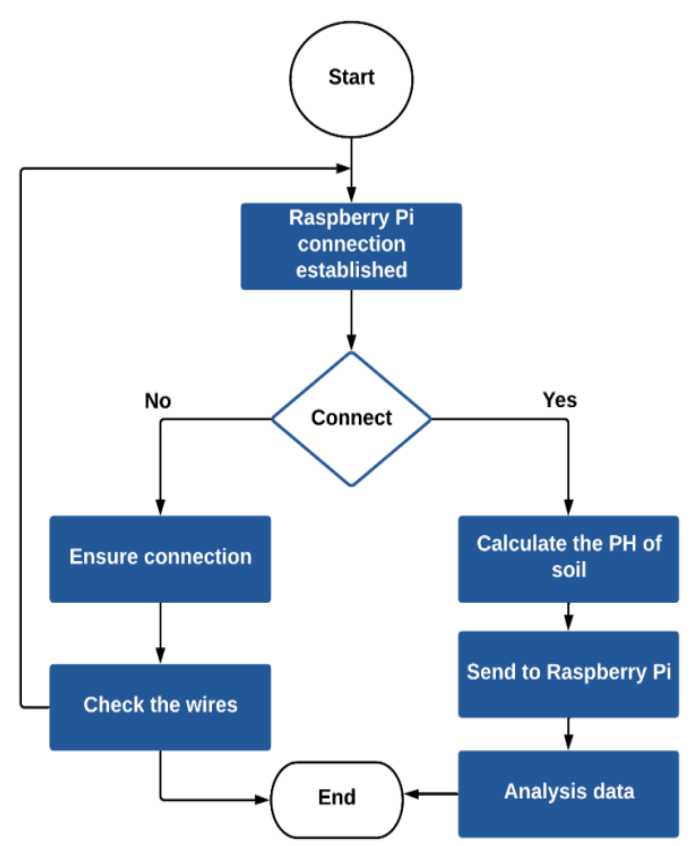

Figure 3. Flow chart for connecting $\mathrm{pH}$ sensor to $\mathrm{Pi}$

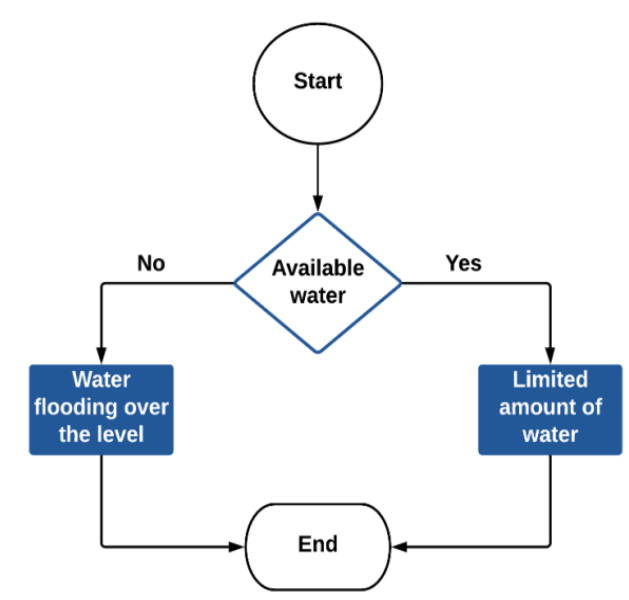

Figure 4. Flow chart for connecting water level sensor to $\mathrm{Pi}$

To connect the DHT11 to raspberry pi, we use exactly same configuration as Figure 5. Since the output is digital, we have no need to use converter to convert the values from analog to digital. First of all we connect the sensor's digital pin to raspberry pi GPIO pin, VCC to 5V dc supply and GND to ground of the pi respectively. Again, we need to use a resistor on the board for controlling the amount voltage level in order to avoid unpredictable accident.

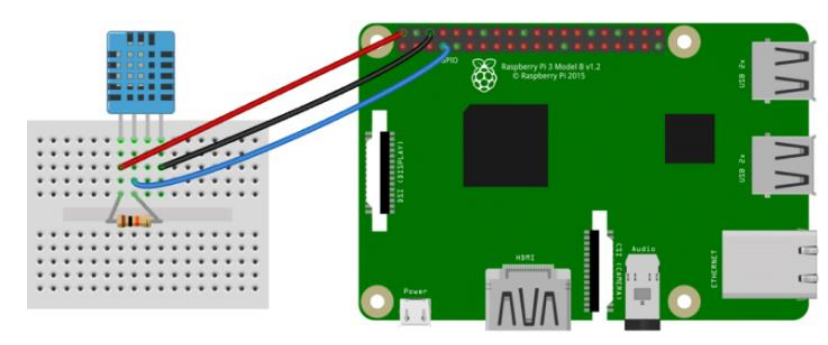

Figure 5. Circuit diagram of soil Humidity and Temperature

Truly, we use this sensor to measure current humidity of air in the field as well as present temperature. The working method of dht11 is as like as the $\mathrm{pH}$ sensor's working procedure.

\subsection{Dashboard Optimization}

Actually, in our research we have used dashboard in order to observe current situation. As far we know that android phone android or application is one of the most popular technology in recent world. In fact every person in our society has an android phone. So, this our motto to develop a wireless system through cloud computing in order to monitor immediately. This is the reason why this develpoed system builds 
upon dashboard. Due to make a server based system, we have used a free acces sever in order to ensure costeffective. To send sensor's data from raspberry pi we have used MQTT protocol [23]. Data is sent from raspberry pi to server using MQTT, then converted into respective dashboard.

The Figure 6 shows live observation of $\mathrm{pH}$, humidity/temperature, water level and soil moisture sensor. Through the dashboard farmers are able to decide when to start the pump for irrigation, if there is much amount of water result in overflow, what is the current temperature and humidity in atmosphere and finally what is the present $\mathrm{pH}$ level of soil. By using these dashboard users are able to know when they have to go on checking the field. Basically, dashboard optimaization makes this project more reliable, effective towards agriculture and simpler for farmers.

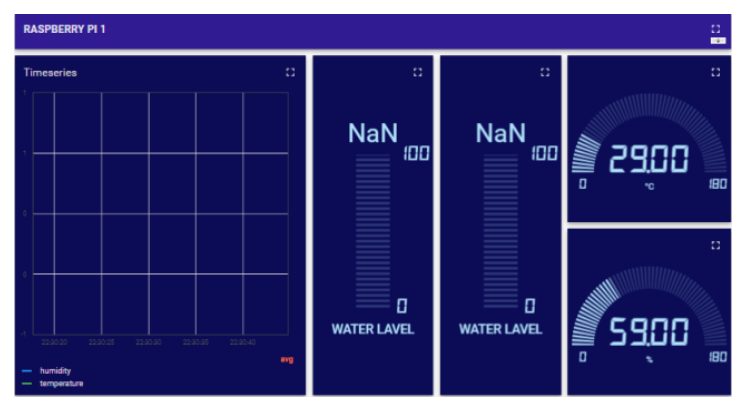

Figure 6. Demo Dashboard for live observation

The working procedure of dashboard is exactly same as Figure 7. Firstly, system will check and double check the internet connection status, if connection is available, it start reading data from sensor send the corresponding values to the cloud. Basically, we use Thingsboard live demo for the construction of dashboard.

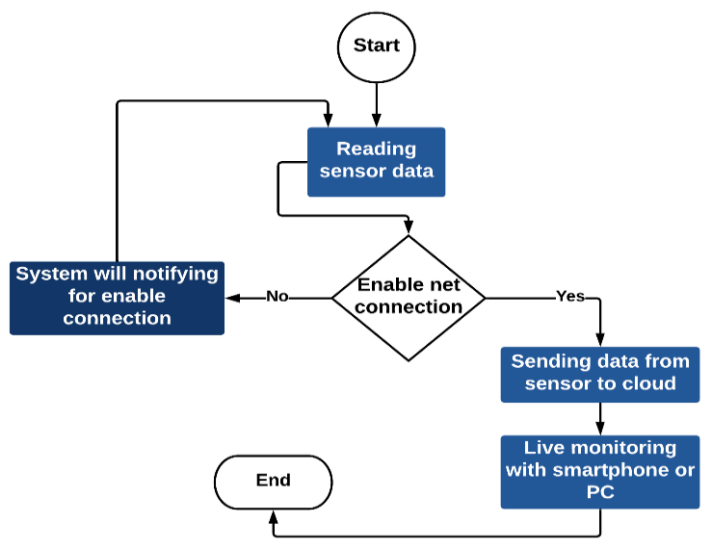

Figure 7. Flow chart to show working procedure of Dashboard

\subsubsection{Security System}

Our developed system offers a strong and cost effective security system [24-25] which is applicable for both day and night. To accomplish this goal, we use low cost laser shield along with IP-Camera module. IP-camera offers a strong security system and laser shield resits an unauthorized access in the farm at night. Suppose, if there is an unauthorized access at light, this system immediately inform the farmers using Wi-Fi. Users are able to see the present condition of the farm using android application as well as taking immediate actions for security issues.

The developed system is much like as Figure 8. Here, we use laser shield around the farm. IPcamera placed at 4 points in developed system. We use Wi-Fi to receive data and send data to the system simultaneously through android application. In future we will add GSM technology to observe live using cloud computing. 


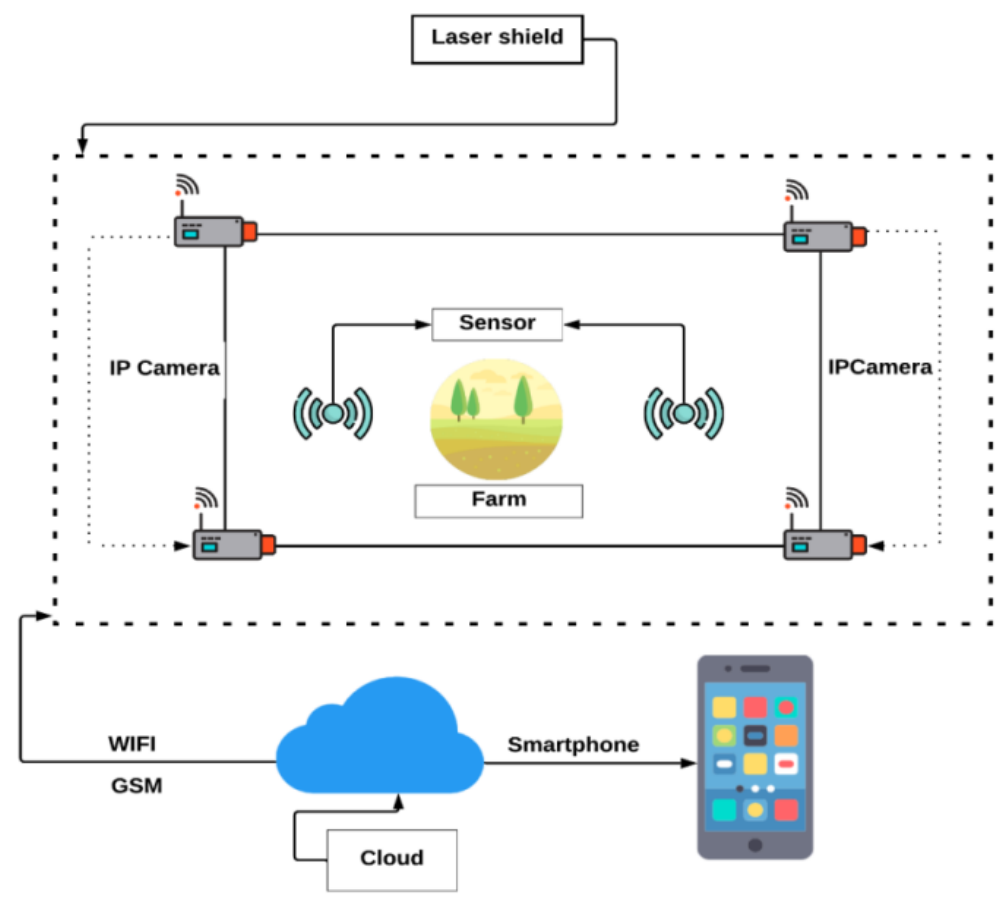

Figure 8. Block diagram of developed security system

\section{RESULT AND DISCUSSION}

This research assures experiments on different type of soils. This experiments have been taken in the region of Tangail Sadar Upazila, Tangail, Dhaka, Bangladesh-1902. Our experiments are classified into two major parts. At first we do experiment to measure the moisture of soil. Finally, we have tried to calculate $\mathrm{pH}$ of soil in the corresponding region.

\subsection{Experiment No. 01}

As we know that soil moisture sensor calculate the moisture using resistance resided in the sensor. There's a potentiometer which controls the certain level of current and measure the corresponding resistance. Hopefully, the values remain in a range between 200-1000. The lower value indicates increased of conductivity or decreased of resistance. The higher value plays the same role but opposite of lower values of measurement.

We have taken 4 sample of soil form 8 particular areas. They are namely Santosh, Ghospara, Sakrail and Kagmari. We found the average value of soil around 781.6. Table 1 shows experimented values and Figure 9 shows bar diagram of the experimented data.

Table 1. Experimented Data by Calculating Moisture of the Soil

\begin{tabular}{ccc}
\hline SL no. & $\begin{array}{c}\text { Sample Name } \\
\text { (Location) }\end{array}$ & $\begin{array}{c}\text { Moisture } \\
\text { of the soil }\end{array}$ \\
\hline 1 & Santosh-1 & 1000 \\
2 & Santosh-2 & 920 \\
3 & Ghospara-1 & 780 \\
4 & Ghospara-2 & 821 \\
5 & Sakrail-1 & 381 \\
6 & Sakrail-2 & 491 \\
7 & Kagmari-1 & 965 \\
8 & Kagmari-2 & 895 \\
\hline
\end{tabular}

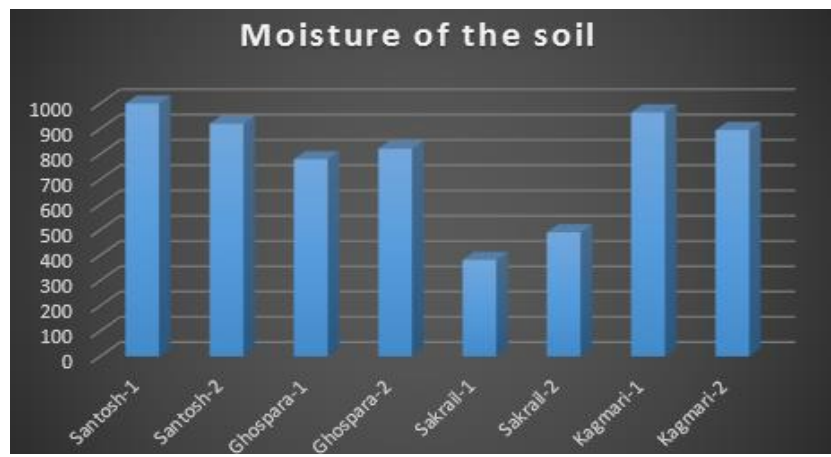

Figure 9. Bar diagram of measured moisture of the soil 


\subsection{Experiment No. 2}

We have done 2nd experiment to calculate the value of $\mathrm{pH}$. We did exact the same experimenst in the region which is previously discussed in the section Experiment No. 1 After successfully completed the examination, we have found that average value of $\mathrm{pH}$ is 5.18. Table 2 and Figure 10 shows experimented data analysis for $\mathrm{pH}$ measurement.

Table 2. Experimented Data by

Calculating $\mathrm{Ph}$ of the Soil

\begin{tabular}{ccc}
\hline $\begin{array}{c}\text { SL } \\
\text { no. }\end{array}$ & $\begin{array}{c}\text { Sample Name } \\
\text { (Location) }\end{array}$ & $\begin{array}{c}\mathrm{pH} \text { of the } \\
\text { soil }\end{array}$ \\
\hline 1 & Santosh-1 & 5.44 \\
2 & Santosh-2 & 5.21 \\
3 & Ghospara-1 & 4.93 \\
4 & Ghospara-2 & 4.98 \\
5 & Sakrail-1 & 5.11 \\
6 & Sakrail-2 & 4.84 \\
7 & Kagmari-1 & 5.38 \\
8 & Kagmari-2 & 5.55 \\
\hline
\end{tabular}

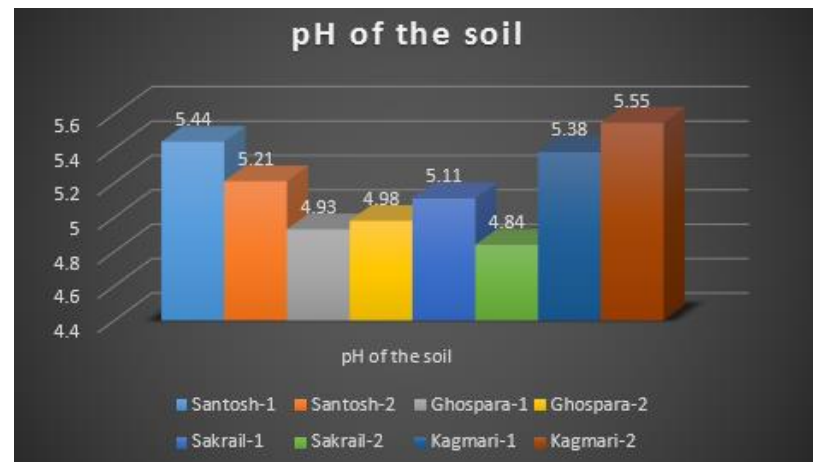

Figure 10. Bar diagram of measured $\mathrm{pH}$ of the soil

\section{CONCLUSION}

A system to focus on real-time observation with efficient use of cheapest security system, live monitoring and the project delivered a chance to learn the obtainable systems, laterally with their features and downsides. Through this system it can be determined that there can be significant number of improvement in farming sectors with the consumption of IOT and computerization. This proposed system can be used for measuring moisture of the filed using soil moisture sensor, detecting flooded water, measuring the $\mathrm{pH}$ of soil and tracking out the present temperature and humidity in the agriculture. Thus, the system would be a feasible explanation to the problems faced in the standing of manual and cumbrous progression of irrigation by allowing effective exploitation of water resources.

\section{REFERENCES}

[1] Lakshmisudha, K., et al. "Smart Precision Based Agriculture Using Sensors." International Journal of Computer Applications 9758887 (2011).

[2] Kumar, V. Vinoth, et al. "Implementation of IOT in smart irrigation system using arduino processor." International Journal of Civil Engineering and Technology 8.10 (2017): 1304-1314.

[3] Nandhini, R., et al. "Arduino based smart irrigation system using IoT" 3rd National Conference On Intelligent Information And Computing Technologies, IICT'17. 2017.

[4] Prabha, Rekha, et al. "Design and Development of an IoT Based Smart Irrigation and Fertilization System for Chilli Farming" 2018 International Conference on Wireless Communications, Signal Processing and Networking (WiSPNET). IEEE, 2018.

[5] Shekhar, Y., Dagur, E., Mishra, S., \& Sankaranarayanan, S. (2017). "Intelligent IoT based automated irrigation system”. International Journal of Applied Engineering Research, 12(18), 7306-7320.

[6] Bhagyashree K. Chate, Prof.J.G. Rana, "Smart Irrigation System Using Raspberry Pi”, International Research Journal of Engineering and Technology (IRJET) e-ISSN: 2395 -0056 Volume: 03 Issue: 05 | May-2016 www.irjet.net p-ISSN: 2395-0072.

[7] Ms. Swapnali B. Pawar, Prof. Priti Rajput, Prof. Asif Shaikh, "Smart Irrigation System Using IOT And Raspberry Pi”, International Research Journal of Engineering and Technology (IRJET) e-ISSN: 2395-0056.

[8] Volume: 05 Issue: 08 | Aug 2018 www.irjet.net p-ISSN: 2395-0072

[9] Karunakanth, M., Venkatesan, R. and Kathrine, G.J.W., 2018. "IOT Based Smart Irrigation System for Home Based Organic Garden". International Journal of Pure and Applied Mathematics, 119(12), pp.16193-16200.

[10] Rawal, S., 2017. "Iot based smart irrigation system". International Journal of Computer Applications, 159(8), pp.880-886.

[11] Ishak, S.N., Malik, N.A., Latiff, N.A., Ghazali, N.E. and Baharudin, M.A., 2017, November. "Smart home garden irrigation system using Raspberry Pi”. In 2017 IEEE 13th Malaysia International Conference on Communications (MICC) (pp. 101-106). IEEE.

[12] Jainishkuamr Anghan, Parveen Sultana H, "Smart Irrigation System using Raspberry Pi”, International Journal of Scientific \& Engineering Research, Volume 9, Issue 6, June-2018 ISSN 2229-5518. 
[13] Maha, M. M., Bhuiyan, S., \& Masuduzzaman, M. (2019, January). "Smart Board for Precision Farming Using Wireless Sensor Network." In 2019 International Conference on Robotics, Electrical and Signal Processing Techniques (ICREST) (pp. 445-450). IEEE.

[14] Cambra, C., Sendra, S., Lloret, J., \& Garcia, L. (2017, May). “An IoT service-oriented system for agriculture monitoring. ” In 2017 IEEE International Conference on Communications (ICC) (pp. 1-6). IEEE.

[15] TongKe, F. (2013). "Smart agriculture based on cloud computing and IOT." Journal of Convergence Information Technology, 8(2).

[16] Maha, M. M., Bhuiyan, S., \& Masuduzzaman, M. (2019, January). "Smart Board for Precision Farming Using Wireless Sensor Network." In 2019 International Conference on Robotics, Electrical and Signal Processing Techniques (ICREST) (pp. 445-450). IEEE.

[17] Deshpande, A. R., Patil, P., Tonape, A., Kadam, M., \& Bhandari, K. (2017). "Smart Farming: Unleashing power of IoT solutions in Indian agricultural system." Journal of Computer Based Parallel Programming, 2(2), 1-7.

[18] Patil, K. A., \& Kale, N. R. (2016, December). “A model for smart agriculture using IoT.” In 2016 International Conference on Global Trends in Signal Processing, Information Computing and Communication (ICGTSPICC) (pp. 543-545). IEEE.

[19] Nayyar, A., \& Puri, E. V. (2016, November). “Smart Farming: IoT Based Smart Sensors Agriculture Stick for Live Temprature and Moisture Monitoring using Arduino Cloud Computing \& Solar Technology." In Conference: The International Conference on Communication and Computing Systems (ICCCS-2016).

[20] Prathibha, S. R., Hongal, A., \& Jyothi, M. P. (2017, March). "IOT Based monitoring system in smart agriculture." In 2017 International Conference on Recent Advances in Electronics and Communication Technology (ICRAECT) (pp. 81-84). IEEE.

[21] Suma, N., Samson, S. R., Saranya, S., Shanmugapriya, G., \& Subhashri, R. (2017). "IOT based smart agriculture monitoring system." International Journal on Recent and Innovation Trends in computing and communication, 5(2), 177-181.

[22] Prathibha, S. R., Hongal, A., \& Jyothi, M. P. (2017, March). "IOT Based monitoring system in smart agriculture." In 2017 International Conference on Recent Advances in Electronics and Communication Technology (ICRAECT) (pp. 81-84). IEEE.

[23] Kodali, R. K., \& Sarjerao, B. S. (2017, July). “A low cost smart irrigation system using MQTT protocol.” In 2017 IEEE Region 10 Symposium (TENSYMP) (pp. 1-5). IEEE.

[24] Baranwal, T., \& Pateriya, P. K. (2016, January). "Development of IoT based smart security and monitoring devices for agriculture." In 2016 6th International Conference-Cloud System and Big Data Engineering (Confluence) (pp. 597-602). IEEE.

[25] Rahman, W., Rashid, H. A., Islam, R., \& Rahman, M. M. (2018). “Embodiment of IOT based Smart Home Security System.” Ijraset. 